\title{
Success Stories in Asia's Quest for Increasing Its Domestic Milk Production
}

\author{
John Moran ${ }^{1}$, Geoff Walker ${ }^{2}$ and Mohammad Abdus Salam ${ }^{3}$ \\ 1. Profitable Dairy Systems, Kyabram 3620, Victoria, Australia \\ 2. Land O Lakes, Dhaka, Bangladesh \\ 3. Bangladesh Dairy Enhancement Program, Bangladesh
}

\begin{abstract}
Throughout the humid tropics of Asia, smallholder dairy (SHD) farmers have developed their production systems largely based on the "traditional way of doing things". Tradition is a generic word used in this case to mean basing farm management decisions and practices on how their father, or friends or even next door neighbours do things. The low levels of milk production and herd fertility, the high incidences of calf mortalities and poor animal health (such as lameness and mastitis) and the inferior quality of much of the milk sourced from these farms are clear indications that many of these traditional farm management practices are in urgent need of re-evaluation. This need not necessarily be the norm and this paper provides two good examples of how innovation can pay off in the humid tropics of Bangladesh. They clearly demonstrated that improving herd management, particularly feeding management, can dramatically increase cow performance with higher milk yields and herd fertility.
\end{abstract}

Key words: Dairy development, milk yield, herd fertility.

\section{Introduction}

Throughout the humid tropics of Asia, smallholder dairy (SHD) farmers have developed their production systems largely based on the "traditional way of doing things". Tradition is a generic word used in this case to mean basing farm management decisions and practices on how their father, or friends or even next door neighbours do things. This is complemented with their own trial and error experiences and maybe some advice from service providers, such as dairy cooperative, government advisers or milk supply officers from commercial dairy processors. Rarely do SHD farmers take full advantage of all the information sources available to them, with many of them available for free [1].

With the rapid increases in knowledge related to herd and feeding management of milking cows, particularly animal welfare and cow comfort, traditions

Corresponding author: John Moran, doctor, director of profitable dairy systems, research field: tropical dairy production technology. soon become outdated. However unlike dairy farmers in developed countries, many Asian farmers do not seem to be as exposed to the latest information or if exposed, do not seem sufficiently receptive to adopt many of the resultant improved farm practices. Perhaps it may be related to their generally poorer level of education (hence lack of awareness of the benefits of such improved farm management practices) and/or the fact that many have insufficient milking cows hence must rely on non-dairy enterprises to generate much of their farm income. Not being "full time" dairy farmers possibly reduces their time and motivation to actively seek and adopt new information and technology.

Traditional dairy farm management practices are then not conducive to high levels of stock performance or farm profits, as is evident from many studies throughout Asia [2-4]. The following lists many of the typical measures of herd performance on traditionally managed smallholder dairy farms in the humid tropics [5]:

- 8 to $10 \mathrm{~kg} / \mathrm{cow} / \mathrm{d}$ of milk, compared to realistic peak milk yields of 15 to $20 \mathrm{~kg} / \mathrm{cow} / \mathrm{d}$; 
- 15 to 18 months calving interval, instead of 12 to 15 months;

- 30 to 36 months age at first calving, rather than 24 to 27 months;

- 2.5 or more services per conception rather than a realistic 1.8 to 2.0 ;

- High mortality rates in young stock, often with little diagnoses of the causes;

- Many cows suffering from obvious climatic stress, as is evidenced by respiration rates exceeding 70 breaths per minute;

- High levels of subclinical, as well as clinical, mastitis;

- High incidence of anoestrus, repeat breeding and lameness;

- High incidences of animal health problems due to poor veterinary support and subsequent practices;

- Unacceptably high levels of bacterial contamination in fresh milk delivered to milk collection centres.

The above KPIs (key performance indicators) are a result of poor management practices. However they are also the outcomes of deficiencies in the farm's physical layout, such as:

- Insufficient year-round supplies, or provision of clean drinking water, for ad libitum intakes;

- Insufficient areas for on-farm forage production;

- Low quality forages arising from poor agronomic practices, such as lack of inorganic fertilisers and lengthy crop harvest intervals;

- Many farmers depending on rice straw;

- Poor quality concentrates arising from contamination of raw ingredients and improper formulation procedures;

- Concentrate ingredients mixed with water prior to feeding out;

- Cattle housing not conducive to cow comfort, for example poor shed ventilation, absence of fans and minimal provision of rubber mats for stock to lie on;

- Tie stalls rather than free stalls or open lounging. This article discusses recent developments in both traditional small holder dairying in Bangladesh and also in more intensive large scale dairy farming in Indonesia.

\section{The Bangladesh Dairy Enhancement Project}

With the many constraints imposed by traditional management practices, we would like to discuss a recent example of a donor funded dairy development program that has taken a lateral thinking approach to SHD and is likely to have a big impact on the long term future of one of the least developed dairy industries in Asia, namely in Bangladesh. This is the BDEP (Bangladesh dairy enhancement program).

The BDEP is a 3-year program run by Land $\mathrm{O}$ Lakes International Development and funded by the USDA. Its major aim is to increase milk production in Bangladesh through a series of initiatives impacting on SHD farmers to demonstrate the beneficial effectiveness of improving WFM (whole farm management) practices, and also to provide them with linkages to the formal milk market (through several milk processors). The program concluded in mid 2017, by which time it has impacted on over 9,000 SHD farmers in the country. For project farmers to meet the targets as set by USDA for successful participation in BDEP, they are expected to have applied at least one of the following 21 improved WFM practices on their farm. For successful dairy farming, however, the more of these they apply, the better the outcome:

- Separate feed and drinking water;

- Provide clean drinking water for 24 hours each day;

- Chop the fodder on offer;

- Feed quality green fodder;

- Make and feed silage during periods of fodder shortages;

- Offer rock salt to provide additional minerals;

- Improve cow housing ensuring adequate ventilation;

- Pay close attention to milking hygiene and ensure 
complete milk harvesting;

- Practice early weaning;

- Ensure daily bathing with a hose, the hotter the day, the more frequent the bathing;

- Provide concentrates that are specifically formulated and nutritionally balanced for milking cows, for example MAB/BDEP formulations;

- Provide colostrum to each new born calf, ensuring it has been consumed;

- Provide CMR (calf milk replacer) rather than whole milk to milk-fed calves;

- Practice good calf management;

- Encourage the development of the weaned heifer's udder through optimum feeding and stock management;

- Encourage the development of the rumen in young stock through optimum feeding management;

- Practice the principles of good farm cleanliness to ensure clean floors and stock with no evidence of lameness and dirty coats;

- Ensure good cow comfort through the provision of sand beds or rubber mats and good ventilation, preferably with electric fans;

- Routinely monitor the animal's live weight and body condition;

- In preparing land for forage production, incorporate compost into the soil;

- Routinely vaccinate and deworm stock according to their body weight.

In addition, entrepreneurs have been assisted to establish "one stop shops" for feeds and services to enhance their cow and herd productivity and hence profitability. These sale outlets are commercially managed by local innovative dairy entrepreneurs (often farmers themselves) and are called Mini-Agribusinesses (MAB). They sell a wide range of necessities for any well managed dairy farm such as:

- Concentrate formulations that are nutritionally balanced and specifically formulated for milking cows;
- Quality green fodder such as immature forage maize, which is harvested at the pre-flowering stage to maximise its protein content, at the expense of single crop yields. This is generally sold as fresh as green chop although some is now being made into silage and stored in bunkers; when ready for use, it is freshly extracted from the stack to be supplied to farmers, generally on a day to day basis;

- Calf milk replacer imported from Europe which, when made into solution, costs about one-third less than the value of raw milk;

- Other dairy farm requisites such as vaccines and deworming tablets, rubber mats and ear tags;

- Farm services, for example testing of mastitis using the California mastitis test;

- Good quality FMD (foot and mouth disease) vaccine.

BDEP conducted a series of on-farm training programs to demonstrate how these enhanced farm management practices can increase farm profits through higher milk production, higher fat content, better fertility and lower veterinary treatment costs. The project has developed and demonstrated how, through improving these cow and herd WFM practices, they can be made to work in practical terms for smallholder farmers.

BDEP has then followed a focused and integrated approach to dairy development, with three components:

- Establishment by dairy companies of milk chilling infrastructure on the farmers' doorsteps;

- Training farmers in an in-depth manner in WFM, with new advisory services located within the dairy processing companies;

- MAB established in the same vicinity to supply animal nutrition through superior concentrate and chopped maize.

All training, from that of advisory staff to farmers has taken place on-farm, a necessary approach given the difficulty of completely changing farming away from traditional practices, and one which allows direct 
contact with the females who do much of the animal husbandry in Bangladesh. BDEP follows a genuine market approach, by its engagement with processing companies (just as happens in developed dairy economies), which have co-invested close to \$3.54 million in milk chilling centers and associated infrastructure. BDEP recognized that in effect practical animal husbandry skills were absent in Bangladesh at the start of the project in 2015, hence has facilitated a long-lasting impact of the project via a group of 80 Dairy Development Officers who will assist the growth of the sector for many years to come. The farmers who have followed the BDEP approach will be role models for others in their community, and the impact of BDEP will continue to grow in the years ahead.

A survey was undertaken on 394 SHD farms in the two regions where the program had been operating. Farmers were asked a series of questions about their herd's performance both before and following an on-farm training program which covered water and feeding management, stock health, calf rearing and cow housing and ventilation. A summary of the key findings is presented in Table 1 . Over $95 \%$ of the cows were crossbreds with the remaining $5 \%$ being considered as local dairy stock.

From Table 1, it is apparent that young stock management was successfully directed towards feeding colostrum within the first hour of life, feeding CMR, early weaning and younger age at first calving while cows conceived sooner after calving and farmers chose to inseminate them rather than use natural mating.

Such improved management practices led to 3.4 and $1.9 \mathrm{~L} / \mathrm{cow} / \mathrm{d}$ higher milk yields respectively in crossbred cows and local cows. The benefits of BDEP management with local cows were much lower which is not unexpected given their lower genetic potential as dairy cows, but also the fact that many local cows are managed under low input/low output conditions.

It is one thing to demonstrate higher cow performance through improved feeding and herd management, it is another thing to develop long term strategies to ensure this has long term benefits. The BDEP has developed a support infrastructure through:

$>$ The commitment of milk processors to keep employing Dairy Development Officers;

> The construction of 75 new milk collection centres;

Table 1 Productive performance of cows on 394 farms before and after on farm training.

\begin{tabular}{lll}
\hline Trait & Before training & After training \\
\hline Calves fed colostrum (\% farmers) & \multicolumn{1}{c}{} \\
$<$ hour & 30 & 97 \\
$1-2$ hours & 2 & 2 \\
$>2$ hours & 0 & 38 \\
\% farmers who fed calf milk replacer & & \\
Average age at weaning (\% farmers) & 1 & 37 \\
$<3$ months & 12 & 20 \\
3 to 6 months & 86 & 43 \\
$>6$ months & & \\
Average age at first calving (\% farmers) & 1 & 29 \\
$<24$ months & 15 & 55 \\
$24-27$ months & 54 & 13 \\
$28-30$ months & 28 & 3 \\
$>30$ months & & 22 \\
Calving to conception (\% farmers) & 0.5 & 70 \\
$<2$ months & 30 & 9 \\
$2-3$ months & 99 & 97 \\
$>3$ months & 38 & 11.8 \\
farmers using artificial insemination & 8.4 & 3.9 \\
Milk yield of crossbreds (L/cow/d) & 2.0 & \\
Milk yield of local cows (L/cow/d) & & \\
\hline
\end{tabular}


> The establishment of 110 MABs to provide “one stop shops” for;

$>$ The provision of quality feeds (both green fodder and formulated concentrates); and

$>$ Animal health provisions;

$>$ For the growing number of SHD farmers wanting to invest in, to reap the many benefits of improved whole farm management.

\section{Performance of Crossbred Cows under Traditional or Improved Management in Bangladesh}

A long term study was undertaken to assess the cow production responses to improve the feeding and farm management of crossbred dairy cows. This involved a total of 65 crossbred dairy cows (either Local $\times$ Friesian or Local $\times$ Jersey) that were selected from 65 small holder farmers from Pabna. The farmers all used traditional feeding and farm management practices hence did not have very productive herds. The cows ranged from 3 to 6 year in age and were all lactating, with some in late lactation. Initial live weights ranged from 220 to $300 \mathrm{~kg}$, with initial body condition scores ranging from 1.5 to 2.5 points out of 5 . Some 25 of these cows were returned to their owners to be managed traditionally while the remaining 40 were run in small groups under an improved management system (based on BDEP principles) for at least 12 months, with some 20 cows managed together for two years or more. Forage and concentrate samples were collected for analyses of DM (dry matter), organic matter, energy, protein and calcium contents while cow live weights (using chest girth tapes) and body condition score were regularly monitored.

The "improved" management system differed from "traditional" systems in the following practices:

- The cows were loose housed with access to sand beds for resting, compared to tie stalls in the traditional system. Close attention was given to effective ventilation in these sheds;

- Cows were provided with clean drinking water for 24 hours each day compared to the traditional practice of only being offered limited water twice daily when mixed with concentrates;

- Cows were routinely fed $20 \mathrm{~kg} /$ day of freshly harvested immature forage maize green chop plus a small amount of rice straw compared to the traditional forage feeding management of being offered whatever forage was available in whatever quantities;

- Close attention was given to ensuring adequate trough space for each cow to feed the chopped forages, with concentrate mix sprinkled over it;

- During the milk rearing phase, all calves were offered 2 L milk/day with those under improved management fed maize powder, rich in starch, to stimulate rumen development hence encourage early weaning off milk;

- The improved system was managed for each cow to have a calf every year, hence lactation lengths were shorter than under traditional management;

- Cows in the improved management system were fed a concentrate mix specifically formulated (by BDEP nutritionists) to achieve target milk yields (and milk fat contents) whereas this was not the case under traditional management. Milking cows were fed 2 to 5 $\mathrm{kg} / \mathrm{cow} / \mathrm{d}$, depending on their target milk yields. The concentrate was formulated to provide $10 \mathrm{MJ} / \mathrm{kg} \mathrm{DM}$ of metabolisable energy and $22 \%$ protein which ideally complements the immature forage maize greenchop with its $8 \mathrm{MJ} / \mathrm{kg} \mathrm{DM}$ of energy and 14\% protein;

- The improved concentrate formulation did not incorporate vitamin and mineral supplements and the stock were offered ad libitum natural (Himalayan) rock salt which contains 84 natural minerals and trace elements. Colloidal minerals and trace elements in this crystalline form are easier for animals to digest, absorb and metabolise;

- Prior to the study, the "improved" management cows were all dewormed and vaccinated for Anthrax and FMD. This was not necessarily the case with the traditional managed cows; 
- All the relevant data from the improved herds were routinely collected and electronically stored each day. This included morning and afternoon milk yields, consumption (that is offered less residual) of concentrates and green fodder and also stock ready to inseminate and those requiring veterinary attention. Such a routine practice is virtually unknown on traditional dairy farms.

Key performance indicators were calculated for all 65 cows and statistically analysed to assess the levels of significance of the differences.

The daily DM intakes of improved management cows were estimated to average about $9 \mathrm{~kg}$ $\mathrm{DM} / \mathrm{cow} /$ day. Although not closely monitored, the traditional cows were often on an unlimited forage supplies and could have been eating more (as high as 13 or $14 \mathrm{~kg} \mathrm{DM} /$ cow/d).

Results from the 40 improved and the 25 traditionally managed cows, and their calves, are presented in the following tables. The level of significance in these Tables is either NS (which is non-significant) or it is ** (which indicates that the difference is highly significant).

Table 2 presents the dairy cow data collected during the study. Cow live weights and lactation lengths were not statistically different whereas there were very large differences in cow productivity. Cows under improved management produced more milk (either per day or over the full lactation) and attained higher peak yields which occurred sooner during early lactation. A 78\% higher full lactation yield, an 83\% higher daily milk yield and a $68 \%$ higher peak milk yield are all clear indicators that improved feeding and herd management is likely to be highly profitable. Unfortunately without "hard" data on feed intakes and feed costs, it is not possible to quantify the level of profit arising from these improved management practices.

The large difference in body condition score indicates that not only are the improved management cows putting "more in the bucket", but they are putting "more on their back" in readiness for their next lactation.

The reproductive performance of the two groups is presented in Table 3 and here the differences are simply "huge". Improved management cows conceive $104 \mathrm{~d}$ (that is more than 3 months) earlier, they require 2 less inseminations to get pregnant and their placenta is released 10 hours sooner after confinement than is the case with traditionally managed cows. These reproductive data for the improved management cows are comparable to that found in many, if not most, dairy farms in developed western countries. Such information should be validated in other areas of

Table 2 Productive performance of two groups of dairy cows in Pabna.

\begin{tabular}{llll}
\hline Trait & Traditional & Improved & Significance \\
\hline Cow live weight (kg) & 317 & 385 & NS \\
Cow body condition score (pt/5) & 2.1 & 3.0 & $* *$ \\
Lactation length (d) & 342 & 325 & NS \\
Total milk yield (L/cow) & 1,826 & 3,254 & $* *$ \\
Daily milk yield (L/c/d) & 5.4 & 9.9 & $* *$ \\
Peak milk yield (L/c/d) & 8.4 & 14.1 & $* *$ \\
Days required to reach peak (d) & 88 & 63 & $* *$ \\
\hline
\end{tabular}

Table 3 Reproductive performance of two groups of dairy cows in Pabna.

\begin{tabular}{llll}
\hline Trait & Traditional & Improved & Significance \\
\hline Gestation period (d) & 283 & 283 & NS \\
Days open (d) & 180 & 76 & $* *$ \\
Services per conception & 3.6 & 1.5 & $* *$ \\
Time to release placenta (hr) & 11.9 & 1.8 & $* *$ \\
\hline
\end{tabular}


Table 4 Calf performance of two groups of dairy cows in Pabna.

\begin{tabular}{llll}
\hline Trait & Traditional & Improved & Significance \\
\hline Birth weight $(\mathrm{kg})$ & 18.4 & 24.3 & $* *$ \\
Weaning age $(\mathrm{d})$ & 206 & 94 & $* *$ \\
Weaning weight $(\mathrm{kg})$ & 80 & 71 & $* *$ \\
Growth rate to weaning $(\mathrm{kg} / \mathrm{d})$ & 0.30 & 0.46 & $* *$ \\
\hline
\end{tabular}

Bangladesh because it nearly seems to be "too good to be true".

The calf performance data are presented in Table 4. Calves born to the improved management cows were heavier at birth and were weaned over 100 days earlier, due to the maize powder stimulating development of the rumen wall thus facilitating rumen metabolism hence giving these calves the ability to live and even thrive on solid feeds. There are large costs involved through the necessity of feeding milk for seven months to calves that have been traditionally reared (that is with no concentrates) yet they still grow more slowly than early weaned calves.

Incidentally, there were considerably more calving difficulties within the 25 traditionally managed cows (11 out of 25) than there were in the improved management cows (only 2 out of 40). This could be due to the poorer pelvic muscular control during the actual parturition process or the lack of vigour of the neonatal calves being born to these traditionally managed cows.

\section{Recent Developments in Large Scale Dairy Farming in Indonesia}

Rather than depend entirely on small holder dairy farming to increase domestic milk production throughout Asia, greater attention is being given to large scale, intensive dairy production systems. For the last decade or so, Indonesia's key large scale dairy farm has been Greenfield's which is located at 1,090 $\mathrm{m}$ altitude in East Java. The farm currently runs a total of 8,600 dairy stock which includes 4,500 milking (and dry) cows. These cows are housed in very large (up to $200 \mathrm{~m}$ long) free stall sheds each equipped with a series of fans that circulate air along their length; these are called ventilation barns. The rolling herd average of the milking herd is currently $32.9 \mathrm{~L} / \mathrm{cow} / \mathrm{d}$ which would be one of the highest and most profitable in South and East Asia. The raw milk is currently valued at 5,700 Rp/L with its cost of production being only 2,800 Rp/L. The milk is processed on site. This farm has become so profitable and successful that plans are now afoot to construct a new farm to house 4,000 more milking cows in East Java, based on the same forage sourcing and intensive feeding systems.

In addition to the new Greenfields feedlot dairy farm, there are plans to develop another five "mega" dairy farms in West Java and Sumatra, with projected milking cow herds ranging from 3,500 up to 12,000 per farm. When completed, these will introduce an additional 34,500 milking cows to Indonesia’s 2015 total dairy stock population of 525,000 animals. Assuming a similar herd structure as at Greenfield's, this will eventually introduce an additional 65,500 dairy cattle to Indonesia's total dairy stock numbers. This is an equivalent to an additional $12 \%$ in dairy cattle numbers being managed under intensive, non-traditional dairy production systems in the republic. One could then conclude that the dairy decision makers and investors in Indonesia have decided that large scale, intensive dairy farming will play an ever increasing role in addressing the republic's future shortfall in fresh milk production. This is highly relevant considering the fact that between 2011 and 2015, fresh milk production has declined by $17 \%$.

\section{The Golden Rules for Tropical Dairy Farming}

A recent innovation in tropical dairy farming has been to crystallise farm management practices into eight "Golden Rules" that cover the entire range of 


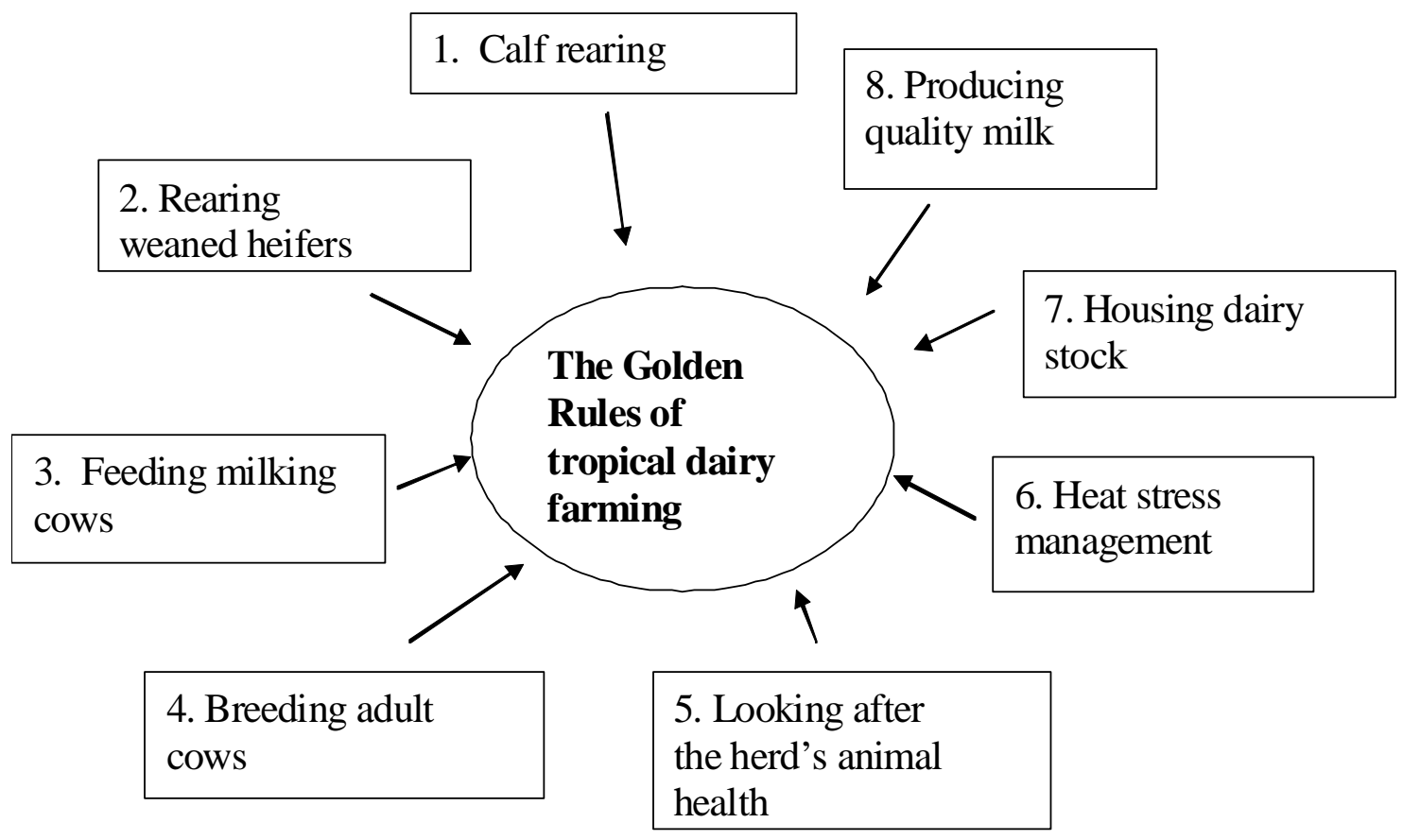

Fig. 1 The eight Golden Rules for tropical dairy farming.

on-farm herd management practices, from rearing young stock and feeding milking cows through to reproductive, animal health, housing and heat stress management, culminating in milking hygiene. These have been summarised graphically in Fig. 1. For each Golden Rule a series of glossy brochures have been developed and summarised by Moran and Chamberlain [5] to provide a simple set of "take home messages" which could easily be translated into the language of the target country.

Forage production has not been included as one of these Golden Rules because of the diversity of soil and climatic variables throughout the tropics and the wide variation in best management practices that can produce quality forages.

\section{Conclusions}

The productive capacity of dairy cows throughout Asia is generally limited by poor adaptation to the tropical environment. The Bangladesh studies reported above clearly demonstrate that these cows will respond positively to the improved whole farm management practices such as that introduced by
BDEP, namely:

- Provision of concentrates formulated for target levels of cow performance;

- Provision of immature maize fodder as produced and chopped by "mini-agribusinesses" established by the project;

- Free access to clean drinking water, supplied in a separate water trough;

- Provision of rock salt;

- Improved cow comfort achieved by cleaner and better ventilated sheds, use of sand beds and/or rubber mats, and temperature mitigation achieved by frequent showering;

- Mastitis management;

- Regular de-worming;

- Regular vaccination against food and mouth disease.

Then milk production is significantly boosted, and reproductive and fertility problems are much reduced.

Further, it is noted that these cows in this Bangladesh study were not raised all their lives under the improved BDEP management practices, so they would have suffered from malnutrition in their early 
life and right up to the start of the project. This was evident from their low body condition scores in the beginning of the study. Therefore, these particular cows will never reach their genetic potential. Accordingly, this study can conclude that higher productivity and higher profitability can be achieved, but that future generations of such cross bred cows will show further gains if they have been well nourished from conception through to their first calving.

The above examples highlight the fact that tradition need not necessarily remain one of the major constraints on many SHD farms in the humid tropics.

\section{References}

[1] Moran, J., and Walker, G. 2017. "How Tradition
Constrains Progress towards the Development of the Dairy Industries of Southern Asia.” Feedapedia.

[2] Ahuja, V., Dugdill, N., Morgan, N., and Tiensin, T. 2012. "Smallholder Dairy Development in Asia and the Pacific." In: Planning Dairy Development Programs in Asia. Proceedings of the Symposium 15th AAAP Congress. Bangkok, Thailand. 77-85. http://www.dairyasia.org/file/Proceedings_dairy.pdf.

[3] Falvey, L., and Chantalakhana, C. 1999. Small Holder Dairying in the Tropics. Kenya: ILRI.

[4] Moran, J., Bernard, J., and Young, A. 2016. "Prioritising Improvements to Traditional Management Practices on Small Holder Dairy Farms in the Humid Tropics of Asia.” Int. J. Agric. Biosciences 5 (2): 73-81.

[5] Moran, J., and Chamberlain, P. 2017. "Blue Prints for Tropical Dairy Farming.” Increasing Domestic Milk Production in Developing Countries. CSIRO Publishing. Melbourne, http://www.publish.csiro.au/ebook/8891. 